\title{
Risk Factors That can Predict Antenatal Insulin Need in Gestational Diabetes
}

\author{
Okan Bakiner ${ }^{\mathrm{a}, \mathrm{d}}$, Emre Bozkirli ${ }^{\mathrm{a}}$, Kursat Ozsahin ${ }^{\mathrm{b}}$, Cagla Sariturk ${ }^{\mathrm{c}}$, Eda Ertorer ${ }^{\mathrm{a}}$
}

\begin{abstract}
Background: This study was undertaken to assess the association between insulin need in gestational diabetes mellitus (GDM) and clinical features and laboratory parameters. Factors that can predict insulin need are also identified.
\end{abstract}

Methods: Cases with GDM were included retrospectively from records. Cases which failed to achieve target blood glucose levels with medical nutrition therapy (MNT) and need insulin treatment were recorded. Risk factors which can predict antenatal insulin treatment (AIT) were identified as follows; the presence of diabetes in a first degree relative, body mass index prior to pregnancy, number of parity, history of GDM, macrosomic baby delivery $(>4,000$ $\mathrm{g}$ ), age, gestational week at time of diagnosis, body mass index during diagnosis, weight gain untill diagnosis, mean systolic and diastolic blood pressure, $\mathrm{HbA} 1 \mathrm{C}$ level during diagnosis, and fasting plasma glucose on diagnostic oral glucose tolerance test. Presence of a statistical significance between those patient features and AIT was assessed. Independent predictors for AIT were evaluated.

Results: A total of 300 cases were recruited from records, 190 cases (63.3\%) were followed only with MNT until delivery and 110 cases (36.7\%) were initiated AIT. The association between AIT and patient factors like presence of diabetes in the pedigree, week of gestation at which GDM was diagnosed, BMI during diagnosis, HbA1C levels, and fasting plasma glucose during diagnosis was found ( $\mathrm{P}$ $=0.03 ; 0.008 ; 0.049 ; 0.001$ and 0.001 respectively $)$. Multivariant

Manuscript accepted for publication July 10, 2013

${ }^{\mathrm{a}}$ Department of Endocrinology and Metabolism Diseases, Baskent University, Faculty of Medicine, Turkey

${ }^{\mathrm{b}}$ Department of Family Medicine Baskent University, Faculty of Medicine, Turkey

${ }^{\mathrm{c}}$ Department of Biostatistics, Baskent University, Faculty of Medicine, Turkey

${ }^{\mathrm{d}}$ Corresponding author: Okan Bakiner, Dadaloglu Mah. Serinevler 2591 Sk., No:4/A 01250 Yuregir/Adana, Turkey.

Email:okanbakiner@mynet.com

doi: http://dx.doi.org/10.4021/jocmr1515w analysis showed that fasting plasma glucose levels during diagnosis and $\mathrm{HbA} 1 \mathrm{C}$ levels were independent risk factors for AIT. Fasting plasma glucose values that can predict AIT were identified $>89.5$ $\mathrm{mg} / \mathrm{dL}$ with $72.7 \%$ sensitivity and $62.6 \%$ spesifity $(\mathrm{P}<0.001)$. Positive predictive value was $73 \%(\mathrm{P}<0.001)$. Also, $\mathrm{HbA} 1 \mathrm{C}$ levels that can predict AIT was found to be $>5.485 \%$ with $65.3 \%$ sensitivity and $66.7 \%$ spesifitiy $(\mathrm{P}<0.001)$ with a positive predictive value $68 \%(\mathrm{P}<0.001)$.

Conclusions: Independent predictors for AIT were found as fasting plasma glucose on OGTT and HbA1c levels during diagnosis in GDM. Cases with fasting plasma glucose $\geq 89.5 \mathrm{mg} / \mathrm{dL}$ or $\mathrm{HbA} 1 \mathrm{C}$ $\geq 5.485 \%$ should be closely followed for AIT in specified centers.

Keywords: Diabetes mellitus; Gestational; Antenatal; Insulin; Risk factors

\section{Introduction}

Gestational diabetes mellitus (GDM) is a glucose metabolism disorder detected during pregnancy [1]. It is closely associated with perinatal outcome [2] and with the risk of developing type 2 diabetes in the future life of both fetus and the mother [3]. Maternal glucose levels demonstrate positive correlation with the risk of poor fetal development $[2,3]$.

Self-glucose monitoring is very useful to maintain glycemic control in GDM [4]. Target glucose levels are $<95$ $\mathrm{mg} / \mathrm{dL}$ at fasting, $<140 \mathrm{mg} / \mathrm{dL}$ at first hour, and $<120 \mathrm{mg} /$ $\mathrm{dL}$ at second hour of starting a meal, according to the recommendations of the Fifth International Workshop Conference on GDM [5]. In the case of a women who do not achieve desired glucose levels with diet and exercise, drug therapy should be given to reduce glucose levels in order to guarantee good fetal development and to minimize neonatal complications [6]. The only drug approved so far by the Food and Drug Administration (FDA) for the use in diabetic pregnant women is insulin [7]. The need for insulin therapy might be a starting point for the characterization of patients with more severe GDM. It has been suggested that improved efficiency of health care delivery in GDM relies on improved risk stratification that would allow for triage to low- or high- 
Table 1. Comparison of Pregestational and Gestational Factors Between Patients With MNT Only and Those With AIT

\begin{tabular}{|c|c|c|c|c|}
\hline & Factors & $\begin{array}{l}\text { Patients with } \\
\text { MNT only ( } \mathrm{n}= \\
\text { 190) }\end{array}$ & $\begin{array}{l}\text { Patients with AIT } \\
(\mathrm{n}=110)\end{array}$ & $\mathbf{P}$ \\
\hline \multirow{5}{*}{$\begin{array}{l}\text { Pregestational } \\
\text { Factors }\end{array}$} & positive family history (n) & $88(46.3 \%)$ & $64(58.2)$ & 0.031 \\
\hline & pregestational BMI $\left(\mathrm{kg} / \mathrm{m}^{2}\right)$ & $26.2 \pm 4.3$ & $27.7 \pm 5.5$ & 0.122 \\
\hline & Parity & $2(1-8)$ & $2(1-8)$ & 0.805 \\
\hline & history of GDM (n) & $46(24.2 \%)$ & $32(29 \%)$ & 0.391 \\
\hline & $\begin{array}{l}\text { macrosomic baby birth } \\
\text { history }(\mathrm{n})\end{array}$ & $11(6.2 \%)$ & $10(\% 9.8)$ & 0.190 \\
\hline \multirow[t]{8}{*}{ Gestational Factors } & age (year) & $32.9 \pm 4.6$ & $32.9 \pm 4.9$ & 0.914 \\
\hline & $\begin{array}{l}\text { diagnosis time (gestational } \\
\text { week) }\end{array}$ & $26.1 \pm 5.1$ & $27.6 \pm 4.4$ & 0.008 \\
\hline & BMI at diagnosis $\left(\mathrm{kg} / \mathrm{m}^{2}\right)$ & $30.2 \pm 4.6$ & $31.6 \pm 4.9$ & 0.049 \\
\hline & $\begin{array}{l}\text { weight gain until diagnosis } \\
(\mathrm{kg})\end{array}$ & $9.2(0-16.2)$ & $8.6(2-18.3)$ & 0.945 \\
\hline & $\begin{array}{l}\text { systolic blood pressure during } \\
\text { diagnosis }(\mathrm{mmHg})\end{array}$ & $114.5 \pm 8.8$ & $113.6 \pm 5.9$ & 0.532 \\
\hline & $\begin{array}{l}\text { diastolic blood pressure } \\
\text { during diagnosis }(\mathrm{mmHg})\end{array}$ & $69.2 \pm 7.9$ & $69.0 \pm 7.9$ & 0.089 \\
\hline & $\begin{array}{l}\text { HbA1C during } \\
\text { diagnosis }(\%)\end{array}$ & $5.3 \pm 0.6$ & $5.6 \pm 0.6$ & 0.001 \\
\hline & $\begin{array}{l}\text { Fasting plasma glucose during } \\
\text { OGTT }(\mathrm{mg} / \mathrm{dL})\end{array}$ & $87.5 \pm 11.2$ & $97.3 \pm 12.1$ & 0.0001 \\
\hline
\end{tabular}

MNT: medical Nutrition Therapy; AIT: Antenatal insulin treatment; Mean \pm Standard deviation, Median (Minimum-Maximum).

er-risk clinics [8]. Antenatal insulin treatment (AIT) is the most resource-intensive management component in GDM, a risk-prediction tool that identifies patients likely to need AIT would have theoretical utility. Some risk factors that indicate insulin therapy for glycemic control in pregnancies complicated by diabetes have been studied before. Diagnosis of diabetes at an early gestational age, fasting glucose levels, presence of obesity or a family history of diabetes or exacerbated fetal growth, are all associated with a more severe degree of glucose intolerance [9-12]. Similarly, evaluation of 100, 75 or $50 \mathrm{~g}$ oral glucose tolerance tests indicates the possible relationship between the severity of disorder and the number of abnormal blood glucose values (above the reference limits) $[13,14]$. The role of glycated hemoglobin (HbA1C) in GDM remains controversial despite there are attempts for correlating this parameter with perinatal outcomes [15].

It seems possible to weigh different levels of glucose intolerance during pregnancy in terms of severity, but it remains uncertain above which threshold the risks for the pregnant woman and especially for the fetus reach a magnitude that requires more intensive and/or detailed monitoring [3]. The objective of the present study is to investigate the factors predicting insulin requirement during GDM and to determine the threshold at which AIT is needed.

\section{Method}

\section{Patient selection}

Pregnant women accepted to the Endocrinology and Metabolism outpatient clinic with the diagnosis of Gestational Diabetes between September 2011 and November 2012, were recruited retrospectively. Between 24th and 28th gestational 
Table 2. Regression Analysis Demonstrating Fasting Glucose Level at OGTT and HbA1C at Diagnosis as Independent Predictors for Insulin Requirement in Gestational Diabetes Mellitus

\begin{tabular}{|c|c|c|c|c|c|c|c|c|}
\hline & \multirow{2}{*}{ B } & \multirow{2}{*}{ S.E. } & \multirow{2}{*}{ Wald } & \multirow{2}{*}{ df } & \multirow{2}{*}{$\mathbf{P}$} & \multirow{2}{*}{ Odd Ratio } & \multicolumn{2}{|c|}{$95 \%$ C.I. for $\operatorname{EXP}(B)$} \\
\hline & & & & & & & Lower & Upper \\
\hline positive family history & 0.351 & 0.367 & 0.918 & 1 & 0.338 & 1.421 & 0.692 & 2.916 \\
\hline $\begin{array}{l}\text { Diagnosis time (gestational } \\
\text { week) }\end{array}$ & -0.046 & 0.044 & 1.115 & 1 & 0.291 & 0.955 & 0.876 & 1.040 \\
\hline $\mathrm{BMI}$ at diagnosis & 0.026 & 0.038 & 0.458 & 1 & 0.499 & 1.026 & 0.952 & 1.106 \\
\hline $\mathrm{HbA} 1 \mathrm{C}$ during diagnosis & 0.680 & 0.316 & 4.635 & 1 & 0.031 & 1.974 & 1.063 & 3.666 \\
\hline $\begin{array}{l}\text { Fasting plasma glucose at } \\
\text { OGTT }\end{array}$ & 0.062 & 0.016 & 14.947 & 1 & 0.0001 & 1.064 & 1.031 & 1.098 \\
\hline Constant & -9.682 & 2.665 & 13.203 & 1 & 0.0001 & 0.000 & & \\
\hline
\end{tabular}

a. Variable(s) entered on step 1 positive family history, time of diagnosis (gestational week), BMI at diagnosis, HbA1C at time of diagnosis, Fasting plasma glucose on OGTT.

week, GDM screening were performed with oral glucose tolerance test (OGTT) according to American Diabetes Association (ADA) 2011 guidelines [16]. Glucose levels were studied from antecubital venous samples just before and at first and second hour of $200 \mathrm{~mL}$ oral glucose solution intake containing $75 \mathrm{~g}$ glucose after 12 hours of fasting. Keeping in accordance with ADA gestational diabetes diagnosis criteria, the presence of at least one of the followings; fasting plasma glucose between 92 and $126 \mathrm{mg} / \mathrm{dL}$, plasma glucose $>180$ $\mathrm{mg} / \mathrm{dL}$ at the first hour and above $153 \mathrm{mg} / \mathrm{dL}$ at second hour during OGTT confirmed diagnosis [16].

The exclusion criteria were defined as having history of previous diabetes mellitus, being diagnosed with diabetes before 24th gestational week. Those who had fasting plasma glucose levels $>126 \mathrm{mg} / \mathrm{dL}$, and/or who had HbA1C levels $>6.5 \%$ at diagnosis, smokers and multiple pregnancies were excluded, as well.

This study was approved by the Ethics Commite of Baskent University (Project no: KA12/278) and was supported by Baskent University Research Fund.

\section{Method}

This was planned as a retrospective observational cohort study. The cases who needed AIT, due to inability in achieving target blood glucose levels with medical nutrition therapy (MNT) [5] were identified and registered. The MNT were prescribed by a registered dietician with respect to
ADA 2011 standarts [16]. It was individualized in respect to pre-pregnancy body mass index (BMI) of the patients. Obesity was defined as BMI, calculated by pre-pregnancy weight $(\mathrm{kg})$ divided by height ( $\mathrm{m}$, squared). Women with a BMI greater than 27 were given $25 \mathrm{kcal} / \mathrm{kg}$ of their actual body weight, those with BMI 20 - 26 were given $30 \mathrm{kcal} /$ $\mathrm{kg}$ and those with BMI less than 20 were prescribed $35 \mathrm{kcal} /$ $\mathrm{kg}$. Physical activity for $30 \mathrm{~min}$ per day was recommended to all patients. Patients were educated to monitor their blood glucose levels. Capillary glucose measurements were performed by the patients at fasting, first and second postprandial hours. The decision for introduction of insulin was considered after evaluation of self-monitoring of blood glucose levels. Target maternal capillary glucose levels were below $96 \mathrm{mg} / \mathrm{dL}$ at fasting, $<140 \mathrm{mg} / \mathrm{dL}$ at $1 \mathrm{~h}$, and $<120 \mathrm{mg} / \mathrm{dL}$ at $2 \mathrm{~h}$ after starting the meal, according to Fifth International Workshop Conference on GDM [17]. Women who failed to achieve target fasting and postprandial glucose levels at the end of two-weeks of follow-up were prescribed insulin.

Patients characteristics from the records which could be decisive for antenatal insulin treatment were identified under two headlines.

\section{Pregestational}

The presence of diabetes mellitus among first degree relatives, BMI before gestation, number of parity, history of GDM in former pregnancies, history of giving birth to a 


\section{ROC Curve}

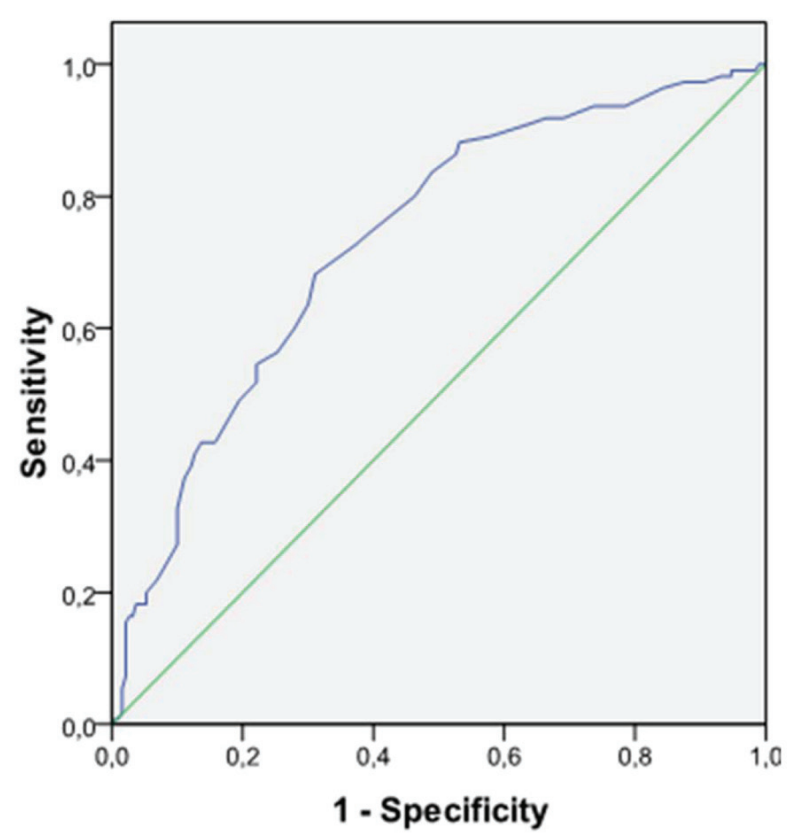

Diagonal segments are produced by ties.

Figure 1. Receiver operating characteristic curve (ROC) exhibiting fasting plasma glucose during OGTT at prediction of insulin requirement. AUC 0.734 , cutofflevel: $89.5 \mathrm{mg} / \mathrm{dL}$, Sensitivity: $72.7 \%$ Specifity: $62.6 \%, P=0.001$

macrosomic baby $(>4,000 \mathrm{~g})$.

\section{Gestational}

Age, gestational week when diabetes was diagnosed, BMI during diagnosis, weight gain untill diagnosis, mean systolic and diastolic blood pressure during diagnosis, $\mathrm{HbA1C}$ and fasting plasma glucose levels atdiagnosis.

Statistical analyses of AIT and patient characteristics mentioned above was performed. Independent predictors and power of prediction between AIT and related patient characteristics through multivariant statistical analysis were inquired, as well.

\section{Assay methods}

After overnight fasting, venous blood samples were withdrawn for determining glucose and HbAlc levels, \% Hemoglobin A1c (DCCT/NGSP) values for human blood samples were obtained on a Roche Modular analyzer (Roche Diagnostics GmbH, Mannheim, Germany) using the Tina-quant Hemoglobin A1c Gen.3 reagent with the hemolysate application. Glucose levels were also mesured on a Roche Modular analyzer using glucose oxidase methodology.

\section{Statistical analysis}

Statistical analysis was performed using the statistical package SPSS v 17.0. For each continuous variable, normality was checked by Kolmogorov Smirnov and Shapiro-Wilk tests and by histograms. Comparisons between gender or BMI were applied using Student T test or One Way ANOVA for normally distrubited data and Mann Whitney U test or Kruscall Wallis test were used for the data not normally distributed. A univariate analysis was done initially, and then clinical variables that were identified as significantly associated with the need for insulin use were included in a multivariate logistic regression. Values of $\mathrm{P}<0.05$ were considered as statistically significant.

\section{Results}

Three-hundred of the 364 hyperglycemic pregnant women who met the inclusion criteria were included in the study. One-hundred ninety $(63.3 \%)$ of cases were followed wih MNT alone and $110(36.7 \%)$ of cases were given antenatal insulin therapy. Table 1 demonstates the comparison of pregestational and gestational factors between patients with 


\section{ROC Curve}

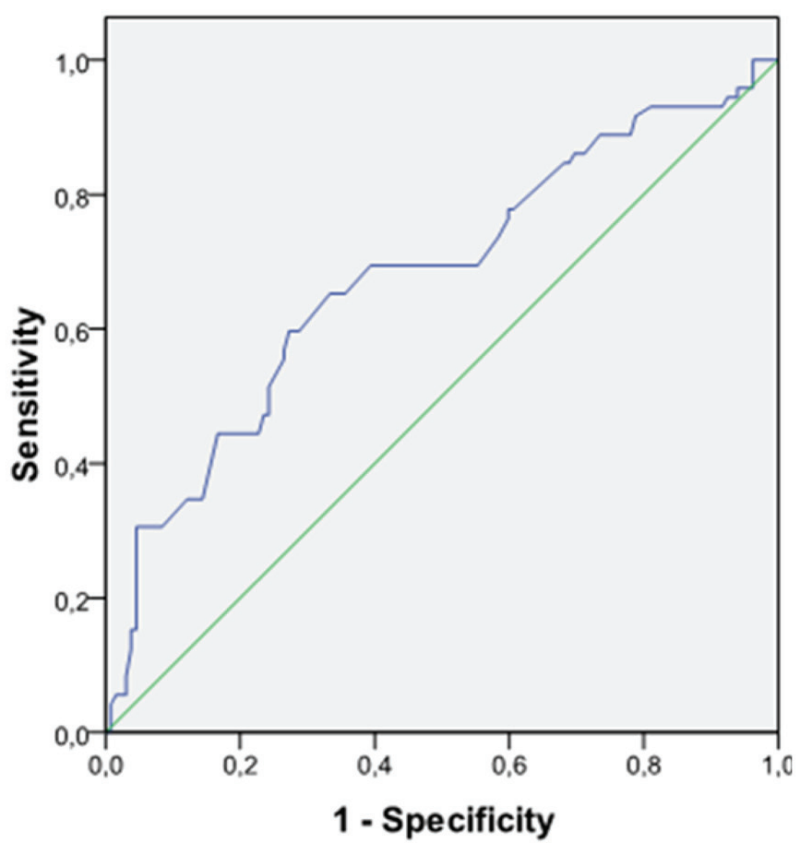

Diagonal segments are produced by ties.

Figure 2. Receiver operating characteristic curve (ROC) demonstrating $\mathrm{HbA} 1 \mathrm{C}$ at diagnosis in prediction of insulin requirement. AUC 0.677 , cutofflevel: $5.485 \%$, Sensitivity: $65.3 \%$, Specifity: $66.7 \%, P=0.001$.

MNT only and those with AIT.

Considering about pregestational factors, the groups exhibited statistically significant difference only with the presence of positive family history of diabetes $(\mathrm{P}=0.031)$. Diabetes was more prevalent among the family members of patients with AIT. Other factors; pregestational BMI, number of parity, history of GDM and giving birth to a macrosomic baby exhibited insignificant difference between the two groups $(\mathrm{P}=0.12, \mathrm{P}=0.80, \mathrm{P}=0.39$ and $\mathrm{P}=0.19$, respectively).

When gestational factors were evaluated, patients with AIT were found to be more obese at diagnosis, $30.2 \pm 4.6 \mathrm{vs}$ $31.6 \pm 4.9 \mathrm{~kg} / \mathrm{m}^{2}(\mathrm{P}=0.049)$. They also had higher HbA1C and fasting plasma glucose during OGTT $(\mathrm{P}=0.001$ and $\mathrm{P}=0.0001$, respectively). Diagnosis time of their diabetes was later than patients with MNT only, $(\mathrm{P}=0.008)$. Other gestational factors; age, weight gain until diagnosis, systolic and diastolic blood pressures were statistically indifferent between the two groups $(\mathrm{P}>0.05)$.

Multivariate analysis demonstrated that fasting glucose level during OGTT and $\mathrm{HbAlC}$ levels at diagnosis were significant predictors for insulin requirement in GDM (Table 2).

Receiver operating characteristic (ROC) curves were generated to determine cut-off values for fasting glucose and
$\mathrm{HbA1C}$ levels at diagnosis to predict insulin requirement (Fig. 1, 2). Accordingly, $72.7 \%$ of women who had fasting glucose level equal to or higher than $89.5 \mathrm{mg} / \mathrm{dL}$ on OGTT required insulin treatment, whereas only $27.3 \%$ of women who had fasting glucose level below $89.5 \mathrm{mg} / \mathrm{dL}$ on OGTT were treated with insulin $(\mathrm{P}=0.001)$. The positive predictive value of fasting glucose value $\geq 89.5 \mathrm{mg} / \mathrm{dL}$ on OGTT was $73 \%$.

Considering about $\mathrm{HbA1C}, 51.6 \%$ of women who had $\mathrm{HbA} 1 \mathrm{C}$ level equal to or higher than $5.485 \%$ at diagnosis required insulin treatment, whereas $22.1 \%$ of women who had $\mathrm{HbA1C}$ level below $5.485 \%$ at diagnosis were treated with insulin $(\mathrm{P}=0.0001)$. The positive predictive value of $\mathrm{HbA1C}$ level $\geq 5.485 \%$ at diagnosis was $68 \%$.

Odds ratio and $95 \% \mathrm{CI}$ for fasting plasma glucose level during OGTT and HbA1C level at diagnosis are given in Table 3.

\section{Discussion}

Gestational diabetes mellitus is an important disorder which has poor outcomes for both fetus and the mother and early stabilisation of glucose levels plays a pivotal role in its man- 
Table 3. Odds Ratio and 95\% Cl for Fasting Plasma Glucose During OGTT and HbA1C at Diagnosis

\begin{tabular}{|c|c|c|c|}
\hline & \multirow{2}{*}{ Value } & \multicolumn{2}{|c|}{ 95\% Confidence Interva } \\
\hline & & Lower & Upper \\
\hline Odds ratio for fasting plasma glucose $(89.5 \mathrm{mg} / \mathrm{dL})$ & 4.469 & 2.678 & 7.460 \\
\hline Odds ratio for $\mathrm{HbA1C}(5.485 \%)$ & 3.760 & 2.053 & 6.887 \\
\hline
\end{tabular}

agement. As insulin is the only tool that is licenced for the management of glucose levels in pregnancy, it is crucial to determine the factors predicting insulin requirement during GDM. In the present study, we clearly demonstrated that family history of diabetes can be a strong prenatal factor for predicting the insulin requirement in GDM. We also showed that more obese women with higher fasting glucose levels during OGTT and higher HbA1c levels at diagnosis required insulin more often. Moreover, fasting glucose level during OGTT and $\mathrm{HbA} 1 \mathrm{C}$ at diagnosis were determined as independent predictors of insulin requirement in GDM. A threshold level of $\geq 89.5 \mathrm{mg} / \mathrm{dL}$ in fasting glucose during OGTT or $\geq$ $5.485 \%$ in $\mathrm{HbA} 1 \mathrm{C}$ at diagnosis were found to distinguish the cases who required insulin in addition to MNT.

Risk factors that indicate the introduction of insulin therapy for glycemic control in pregnancies complicated by GDM have been studied before. However, a few studies have addressed the predictive value of these factors in these subjects. Some of them have demonstrated the impact of fasting plasma glucose during OGTT on insulin requirement in GDM. A study has shown that women with fasting glucose at or below $95 \mathrm{mg} / \mathrm{dL}$ can achieve good glycemic control only after 2 weeks of MNT [17]. Another study has suggested that a fasting glucose level of $87 \mathrm{mg} / \mathrm{dL}$ can effectively predict the need for insulin with a sensitivity of $89.1 \%$ when compared with the $1-$ or $2 \mathrm{~h}$ values on $75 \mathrm{~g}$ OGTT during pregnancy [18]. Langer [9] has found strong positive correlation between fasting glucose above $105 \mathrm{mg} / \mathrm{dl}$ and maternal-perinatal complications, such as; fetal macrosomia, neonatal hypoglycemia, hypertensive syndromes and cesarean delivery. They have concluded that fasting glucose levels above this cut-off are indicative for starting insulin therapy. Additionally, they report that only $70 \%$ of pregnant women with fasting glucose below $95 \mathrm{mg} / \mathrm{dL}$ can achieve satisfactory glycemic control only with diet programs. Akinci and colleguages have also demonstrated statistically significant correlation between fasting glucose levels above $105 \mathrm{mg} / \mathrm{dL}$ and AIT in GDM [19]. The data given in details above is in accordance with our findings and indicates fasting glucose as a potent predictor of antenatal insulin treatment in GDM. However, different cut-off values may be related to methodology of studies, various target glucose levels or ethnic differences.

Like fasting glucose levels on OGTT, Glycated hemoglobin $(\mathrm{HbA} 1 \mathrm{C})$ has been clearly shown to be useful for prediction of insulin requirement and fetal growth in pregnant cases [15]. In our study, $\mathrm{HbA1C}$ predicted poor glycemic control in GDM as reported by Gonzalez-Quintero and Sapienza $[10,11]$. More recently, Clayton and co-workers have demonstrated that higher $\mathrm{HbA1C}$, fasting blood glucose, and BMI values are related with AIT in GDM. The use of clinical markers to assess glycemic control early in pregnancy may lead to the earlier identification of women at risk for GDM and earlier introduction of interventions that can decrease the risk for complications [12].

Women with GDM have been demonstrated to have defects both in insulin sensitivity and insulin secretion [20]. The predictive value of fasting glucose for insulin requirement, which is also shown in our study, suggests that the impact of defect in basal insulin secretion is more obvious. Accordingly, Di Cianni et al [21] have shown that women with one abnormal glucose level at fasting on OGTT are characterized with impairment in basal insulin secretory capacity. On the other hand, HbA1c reflects a longer duration of glycemic control and appears to be useful when performed periconceptionally to estimate the risk of congenital anomalies. It does not seem to confer substantial benefit for estimating the risk of fetal overgrowth or other adverse pregnancy outcomes [22]. However, it may be used as a potent predictor of insulin requirement in women GDM, as demonstrated in the present study.

In this study, the positive predictive value of fasting glucose level $\geq 89.5 \mathrm{mg} / \mathrm{dL}$ during OGTT and $\mathrm{HbA1C}$ level $\geq$ $5.485 \%$ at diagnosis were found to be $73 \%$ and $68 \%$, respectively. These relatively low percentages can be considered as weak for being specific predictors for AIT in GDM and they may be attributed to the following factors: The retrospective design of our study is a limitation for controlling the dietary 
compliance of the participants. Besides, unmeasured fetal or placental factors that influence insulin resistance may have a greater impact on antenatal insulin treament. Finally, selfmonitoring capillary glucose measurements were used and decision of introduction of insulin was given accordingly. Kestila and co-workers have shown that continuous glucose monitoring system detects a markedly higher proportion of GDM mothers needing antihyperglycemic medication compared with self-monitoring of plasma glucose [23]. However, daily self-monitoring of blood glucose is useful in gestational diabetes, as suggested at Fifth International Workshop Conference on GDM [5].

In conclusion, considering about the individual differences in severity of glucose intolerance among women with GDM, they should be classified in such a way that will permit the adoption of specific management for each subgroup. Thus, human and financial resources can be applied more appropriately to groups presenting a higher risk of perinatal complications. Our study helps to create awareness of a low and high risk pregnant women for antenatal insulin therapy. Higher fasting plasma glucose during OGTT and $\mathrm{HbA1C}$ at diagnosis may better be monitored more closely by specified physicians.

\section{Conflict of Interest}

The authors have no conflict of interest.

\section{References}

1. Standards of medical care in diabetes--2008. Diabetes Care. 2008;31(Suppl 1):S12-54.

2. Crowther CA, Hiller JE, Moss JR, McPhee AJ, Jeffries WS, Robinson JS. Effect of treatment of gestational diabetes mellitus on pregnancy outcomes. N Engl J Med. 2005;352(24):2477-2486.

3. Metzger BE, Lowe LP, Dyer AR, Trimble ER, Chaovarindr U, Coustan DR, Hadden DR, et al. Hyperglycemia and adverse pregnancy outcomes. N Engl J Med. 2008;358(19):1991-2002.

4. Davidson J. Strategies for improving glycemic control: effective use of glucose monitoring. Am J Med. 2005;118(Suppl 9A):27S-32S.

5. Metzger BE, Buchanan TA, Coustan DR, de Leiva A, Dunger DB, Hadden DR, Hod M, et al. Summary and recommendations of the Fifth International WorkshopConference on Gestational Diabetes Mellitus. Diabetes Care. 2007;30(Suppl 2):S251-260.

6. Langer O, Rodriguez DA, Xenakis EM, McFarland MB, Berkus MD, Arrendondo F. Intensified versus conventional management of gestational diabetes. Am J Obstet Gynecol. 1994;170(4):1036-1046; discussion 1046-1037.
7. Jovanovic L, Pettitt DJ. Treatment with insulin and its analogs in pregnancies complicated by diabetes. Diabetes Care. 2007;30(Suppl 2):S220-224.

8. Flack JR, Ross GP, Ho S, McElduff A. Recommended changes to diagnostic criteria for gestational diabetes: impact on workload. Aust N Z J Obstet Gynaecol. 2010;50(5):439-443.

9. Langer O. Maternal glycemic criteria for insulin therapy in gestational diabetes mellitus. Diabetes Care. 1998;21(Suppl 2):B91-98.

10. Gonzalez-Quintero VH, Istwan NB, Rhea DJ, Tudela CM, Flick AA, de la Torre L, Stanziano GJ. Antenatal factors predicting subsequent need for insulin treatment in women with gestational diabetes. J Womens Health (Larchmt). 2008;17(7):1183-1187.

11. Sapienza AD, Francisco RP, Trindade TC, Zugaib M. Factors predicting the need for insulin therapy in patients with gestational diabetes mellitus. Diabetes Res Clin Pract. 2010;88(1):81-86.

12. Clayton W, Jr., Agarwal N, Wang L, Jagasia S. Clinical markers implying the need for treatment in women with gestational diabetes mellitus. Endocr Pract. 2012;18(1):62-65.

13. Ergin T, Lembet A, Duran H, Kuscu E, Bagis T, Saygili E, Batioglu S. Does insulin secretion in patients with one abnormal glucose tolerance test value mimic gestational diabetes mellitus? Am J Obstet Gynecol. 2002;186(2):204-209.

14. Kafkasli A, Selcuk SA, Dogan EB,. Burak K, Yologlu FS. Abnormal glucose challenge test and mild gestational diabetes, Gynaecol. Perinatol. 2008; 17 (1): 3-8.

15. Lapolla A, Dalfra MG, Bonomo M, Castiglioni MT, Di Cianni G, Masin M, Mion E, et al. Can plasma glucose and $\mathrm{HbAlc}$ predict fetal growth in mothers with different glucose tolerance levels? Diabetes Res Clin Pract. 2007;77(3):465-470.

16. Standards of medical care in diabetes--2011. Diabetes Care. 2011;34(Suppl 1):S11-61.

17. McFarland MB, Langer O, Conway DL, Berkus MD. Dietary therapy for gestational diabetes: how long is long enough? Obstet Gynecol. 1999;93(6):978-982.

18. Juutinen J, Hartikainen AL, Bloigu R, Tapanainen JS. A retrospective study on 435 women with gestational diabetes: fasting plasma glucose is not sensitive enough for screening but predicts a need for insulin treatment. Diabetes Care. 2000;23(12):1858-1859.

19. Akinci B, Celtik A, Yener S, Yesil S. Is fasting glucose level during oral glucose tolerance test an indicator of the insulin need in gestational diabetes? Diabetes Res Clin Pract. 2008;82(2):219-225.

20. Buchanan TA. Pancreatic B-cell defects in gestational diabetes: implications for the pathogenesis and prevention of type 2 diabetes. J Clin Endocrinol Metab. 2001;86(3):989-993. 
21. Di Cianni G, Seghieri G, Lencioni C, Cuccuru I, Anichini R, De Bellis A, Ghio A, et al. Normal glucose tolerance and gestational diabetes mellitus: what is in between? Diabetes Care. 2007;30(7):1783-1788.

22. Hawkins JS. Glucose monitoring during pregnancy.
Curr Diab Rep. 2010;10(3):229-234.

23. Kestila KK, Ekblad UU, Ronnemaa T. Continuous glucose monitoring versus self-monitoring of blood glucose in the treatment of gestational diabetes mellitus. Diabetes Res Clin Pract. 2007;77(2):174-179. 